\title{
Some Endocrine Traits of Transgenic Rabbits. I. Changes in Plasma and Milk Hormones
}

\author{
A. V. SIROTKIN ${ }^{1}$, P. CHRENEK ${ }^{1}$, J. RAFAY ${ }^{1}$, R. OMELKA ${ }^{2}$, H. VETR $^{3}$, R. JURČÍI ${ }^{1}$, \\ B. R. BINDER ${ }^{3,4}$
}

${ }^{1}$ Research Institute of Animal Production, Slovak Agricultural Research Centre, Nitra, Slovakia,

${ }^{2}$ Department of Botany and Genetics, Constantine the Philosopher University, Nitra, Slovakia,

${ }^{3}$ Technoclone GmbH, Vienna, Austria, ${ }^{4}$ Department of Vascular Biology and Thrombosis Research, Medical University of Vienna, Vienna, Austria

Received October 6, 2006

Accepted July 24, 2007

On-line October 11, 2007

\begin{abstract}
Summary
The aim of these studies was to compare some endocrine and non-endocrine characteristics of transgenic (carrying mammary gland-specific mWAP-hFVIII gene construct) and non-transgenic rabbits. The concentrations of corticosterone, progesterone, testosterone, estradiol, insulin-like growth factor I (IGF-I) and human factor VIII (hFVIII) in the blood plasma of adult females (9 months of age, 3rd generation transgenic animals), adult males, and young females (1-2 months of age, 4th generation of transgenic animals), as well as in the milk of lactating adult females, were analyzed by using RIA. In addition, litter size and body mass of pups born by transgenic and non-transgenic females from the 3rd generation were compared. Transgenic animals were compared with their non-transgenic siblings (the same genetic and epigenetic background). Transgenesis did not influence plasma hFVIII, but significantly increased corticosterone (in all animals), reduced IGF-I (in adult males and females), testosterone and estradiol, (in young females) and altered progesterone (increase in adult males and decrease in adult females) concentrations in blood plasma. In addition, transgenic females had higher milk concentrations of testosterone, but not progesterone or IGF-I than their nontransgenic sisters. These endocrine changes were not associated with changes in litter size. Transgenic male (but not female) pups have smaller body mass than control animals. These observations demonstrate the influence of transgenesis per se on the animal growth and endocrine system (secretion of reproductive and stress steroid hormones as well as growth factors) over four generations.
\end{abstract}

\section{Key words}

Transgenesis - Factor VIII - Progesterone - Testosterone • Estradiol • IGF-I • Corticosterone

\section{Corresponding author}

Alexander V. Sirotkin, Research Institute of Animal Production, Slovak Agricultural Research Centre, Hlohovska 2, 94992 Nitra, Slovakia. Fax: +421-37-6546480. E-mail: sirotkin@scpv.sk

\section{Introduction}

Production of transgenic organisms plays a key role in modern biotechnology and in the pharmaceutical industry. Transgenesis is used mainly for the production of specific biologically active substances, which are accumulated in the cells or released into blood, milk or incubation media. Most publications on transgenic organisms deal with the quantity and quality of produced recombinant proteins, and not with the effects of transgenesis per se on the physiological state of recipients. Both specific and non-specific action of transgenesis on target organs and physiological processes is reported (Lo et al. 1999, Davey and MacLean 2006, Palmer et al. 2006). Nevertheless, despite their great importance, the consequences of introduction of foreign gene constructs on the physiological state, especially over several generations, have been insufficiently examined. Transgenic rabbits could be used not only as a source of animal products or recombinant proteins, but also as models for the study of the influence of foreign genes and transgenesis itself on living processes (Bősze et al. 2003). Such a model could be transgenic rabbits in which the mammary gland produces human factor VIII (hFVIII), the anti-hemophilic A factor (Tuddenham et al. 1991). Rabbits with the mWAP-hFVIII gene, which is shown to 
be integrated into the majority of cells but which induces production of recombinant hFVIII only in mammary gland (Chrenek et al. 2005a,b), have been produced and analyzed in our Institute over four generations. It was observed that the founders transmitted mWAP-hFVIII to their offspring in a Mendelian fashion (Chrenek et al. 2005a). The presence of mWAP hFVIII increased the incidence of pathological changes in organs, blood leucocyte concentration and aneuploidy (Suvegová et al. 2004, Parkányi et al. 2005), the appearance of new type bone tissue and increase in bone marrow cell aneuploidy (Martiniaková et al. 2005), and altered the mobility, concentration, osmolarity and viability of sperm, but did not influence its fertility (Chrenek et al. 2007). The effect of this gene on rabbit female reproductive traits has not been reported.

The endocrine system is responsible for the control of reproduction, adaptation and a number of other biological processes. In rabbits, as in other mammals, gonadal hormones could be both regulators and markers of the state of the reproductive system (Spies et al. 1997, Hillier 2001). Adrenal corticosteroids play an important role in adaptation and stress (DeKloet 2004). In rabbits, a large corticosterone surge is associated with stress and inhibition of reproduction (Viau 2002, Brecchia et al. 2006) and growth (Aghajafari et al. 2002). Growth factors, especially insulin-like growth factor I (IGF-I), have not yet been described in rabbit blood. Nevertheless, in mammals (including rabbits) IGF-I is a known stimulator of growth and meat production (Oksbjerg et al. 2004), gonadal development, ovarian folliculogenesis, oocyte maturation (Fair 2003, Mazerbourg et al. 2003), and ovarian cell proliferation and steroidogenesis (Makarevich et al. 2000). The association of mWAPhFVIII with changes in the secretion of hormones and growth factors regulating reproduction and growth has not yet been studied.

The aim of the present work was to compare the secretion of hormones and IGF-I in transgenic (mWAP-hFVII) and non-transgenic rabbits in relation to their fertility and growth in vivo.

\section{Methods}

In our experiments we have examined

(1) the concentrations of gonadal steroid hormones (progestagen progesterone, androgen testosterone, estrogen estradiol-17beta), the 'stressor' steroid hormone corticosterone and growth factor IGF-I in the plasma of transgenic and non-transgenic adult rabbits,

(2) the concentration of these molecules in the plasma of young, sexually immature transgenic and nontransgenic females,

(3) the concentrations of $\mathrm{P}_{4}, \mathrm{~T}$ and IGF-I in the milk of adult lactating transgenic and non-transgenic animals,

(4) the litter size (number of pups) of transgenic and non-transgenic females,

(5) the body mass of these pups (at one month of age).

Animals

New Zealand White broiler line rabbits from the Slovak Agricultural Research Centre were used. The animals were housed in individual flat-deck wire cages, under a constant photoperiod of $14 \mathrm{~h}$ light per day. The temperature and humidity of the building were recorded continually by means of a thermograph positioned at the same level as the cages. The rabbits were fed ad libitum with a commercial diet and water was provided ad libitum from nipple drinkers. Rabbits were bred in the standard industrial conditions for intensive breeding of broiler rabbits.

Transgenic rabbit founders carrying a mammary gland specific construct consisting of a $2.5 \mathrm{~kb}$ murine whey acidic protein promoter (mWAP), $7.2 \mathrm{~kb}$ cDNA of the human clotting factor VIII (hFVIII), and $4.6 \mathrm{~kb}$ of 3 , flanking sequences of mWAP gene provided by Dr. H. Lubon (American Red Cross, MD, USA) were used (Chrenek et al. 2005a). To obtain the $\mathrm{F}_{3}$ generation, transgenic females from the $\mathrm{F}_{2}$ generation were bred with non-transgenic males. The $\mathrm{F}_{4}$ generation was produced by breeding transgenic females no. 1-3-5 with nontransgenic male (line I) and transgenic females no. 1-9-7 with transgenic male (line II). In our experiment we analyzed both transgenic and non-transgenic offspring, each from the same litters from generation $F_{3}$ (adult sexually mature males and females 9 months of age) and $\mathrm{F}_{4}$ (young, immature females, 1-2 months of age).

\section{Detection of transgene}

Total DNA was isolated from the ear tissue of newborn rabbits and subjected to PCR analysis for the amplification of the hFVIII transgene as reported by Chrenek et al. (2005a), using primers hFVIII-F: 5'-GTA GAC AGC TGT CCA GAG GAA-3' and hFVIII-R: 
5'-GAT CTG ATT TAG TTG GCC CAT C-3' which define a 578 bp region of human FVIII cDNA.

\section{Animal treatment and sample collection}

Blood from young ( 2 months of age) transgenic or non-transgenic females and adult (9 months of age) transgenic or non-transgenic males from the same litter was collected three times at intervals of 2 days, always between 10.00 and 14.00. Blood from adult transgenic or non-transgenic females from the same litter was collected one hour after stimulation of superovulation by i.m. injection of pregnant mare serum gonadotropin (PMSG, Werfaser, Alvetra und WERFFT, Vienna, Austria, $20 \mathrm{IU} / \mathrm{kg}$ body mass). Blood was aspirated by syringe from the central ear vein, collected into heparinized tubes, centrifuged by $2000 \mathrm{x} \mathrm{g}$, and the resultant plasma frozen at $-80{ }^{\circ} \mathrm{C}$ to await RIA.

Milk samples (2-4 $\mathrm{ml}$ per sample) were taken from lactating transgenic and non-transgenic female rabbits on days 10, 20 and 30 of lactation and processed as reported previously (Chrenek et al. 2005a). In order to stimulate milk down, intramuscular injection of $5 \mathrm{IU}$ of oxytocin (Veyx Pharma, Germany) was applied $10 \mathrm{~min}$ before milk collection. The milk was immediately centrifuged at $5000 \mathrm{x}$ g for $10 \mathrm{~min}$, and the upper lipid layer was removed. The samples were stored at $-80^{\circ} \mathrm{C}$ until RIA.

\section{Hormone analysis}

Concentrations of progesterone $\left(\mathrm{P}_{4}\right)$, testosterone (T), estradiol $\left(\mathrm{E}_{2}\right)$, corticosterone $(\mathrm{C})$ and insulin-like growth factor I (IGF-I) in 20-50 $\mu \mathrm{l}$ of blood plasma and milk was measured using RIA/IRMA kits from DSL (Webster, TX, USA) according to the manufacturer's instructions. The characteristics of the assay were described previously (Sirotkin et al. 1998, Makarevich et al. 2004). The concentration of rhFVIII in $200 \mu \mathrm{l}$ of plasma was determined by using an ELISA kit (Asserachrom FVIII:Ag) from Diagnostica Stago (Asniers-sur-Seine, France) according to the manufacturer's instructions. No cross-reactivity of mouse monoclonal antiserum against rhFVIII used with any infectious agents, rheumatoid and growth factors and hormones was detected.

\section{Statistics}

Hormones were analyzed in the blood of 18 adult animals (transgenic: 5 males and 3 females, non-transgenic: 6 males and 4 females) and of 18 young rabbits (transgenic: 4 males and 6 females, non-transgenic: 4 males and 4 females). Milk was collected from 3 transgenic and 3 non-transgenic females. Quantitative data were processed by standard statistical methods. Differences between the groups (transgenic and non-transgenic animals of the same age and sex) were determined by Duncan test by using the computer programmes SigmaStat and SigmaPlot 9.0. (Systat Software, Inc., Erkrath, Germany). Differences at $\mathrm{P}<0.05$ were considered as significant.

\section{Results}

Concentration of hormones in plasma of adult transgenic and non-transgenic males and females

RIA revealed the presence of substantial amounts of $\mathrm{C}, \mathrm{P}_{4}, \mathrm{~T}, \mathrm{E}_{2}$ and of low amounts of rhFVIII immunoreactivity in plasma of both transgenic and nontransgenic rabbits. Relatively high IGF-I concentrations were detected in plasma of control, but not of transgenic animals.

Males had lower concentration of $\mathrm{C}$ than females. Transgenic rabbits, both males and females, had increased concentrations of plasma $\mathrm{C}$ compared with nontransgenic animals (Fig. 1a).

Analysis of IGF-I showed that transgenic males and females had extremely low plasma concentrations of this growth factor (Fig. 1b)

Analysis of gonadal steroid hormones revealed substantial sexual differences: females had more progestagen $\mathrm{P}_{4}$ and estrogen $\mathrm{E}_{2}$ and less androgen $\mathrm{T}$ in comparison to males. Transgenic males had enhanced plasma concentrations of $\mathrm{P}_{4}$ compared to non-transgenic animals of the same sex. However, transgenic females had reduced plasma $\mathrm{P}_{4}$ concentration (Fig. 1c). No significant differences between transgenic and nontransgenic animals (either males or females) in plasma $\mathrm{T}$ (Fig. 1d) or $E_{2}$ (Fig. 1e) were observed.

No differences in plasma rhFVIII immunoreactivity were found between sexes and groups (transgenic and non-transgenic animals, Fig. 1f).

Concentration of hormones in plasma of young transgenic and non-transgenic females

The blood of young animals contained substantially less $\mathrm{C}, \mathrm{P}_{4}$ and $\mathrm{E}_{2}$ and more IGF-I and T, than that of adult females (Fig. 2). Transgenic young females, like adult animals, had higher plasma concentrations of $\mathrm{C}$ than non-transgenic (Fig. 2a). 
A.

Plasma corticosterone level in normal and transgenic male and female rabbits

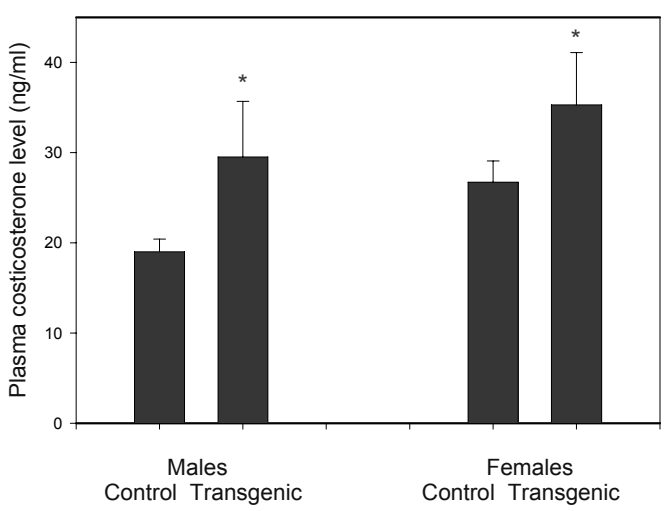

C.

Plasma progesterone level in normal and transgenic male and female rabbits

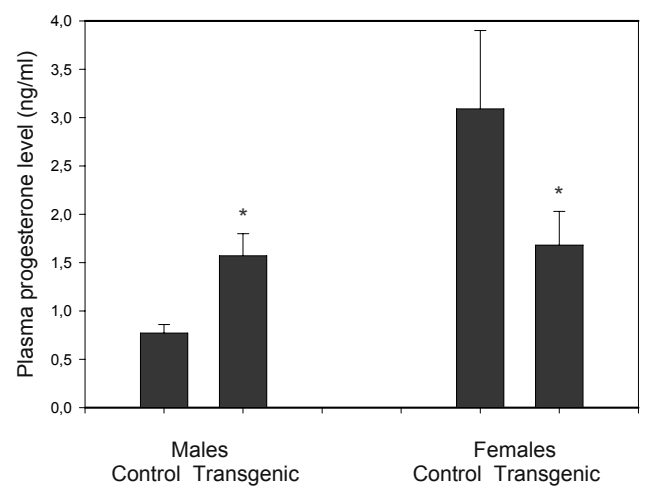

E.

Plasma estradiol leve in normal and transgenic male and female rabbits

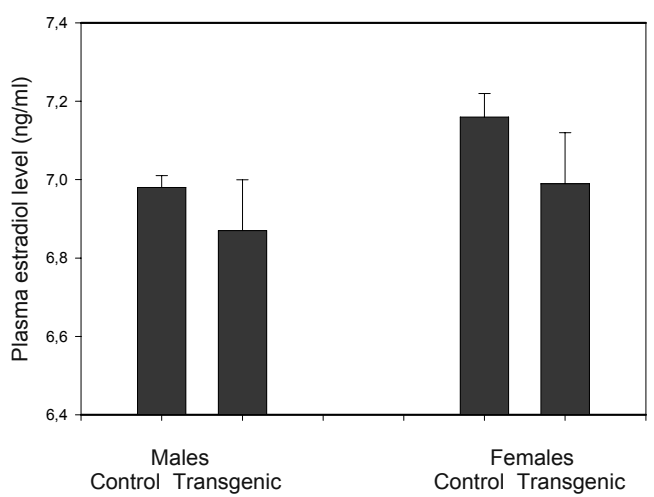

B.

Plasma IGF-I level

in normal and transgenic male and female rabbits

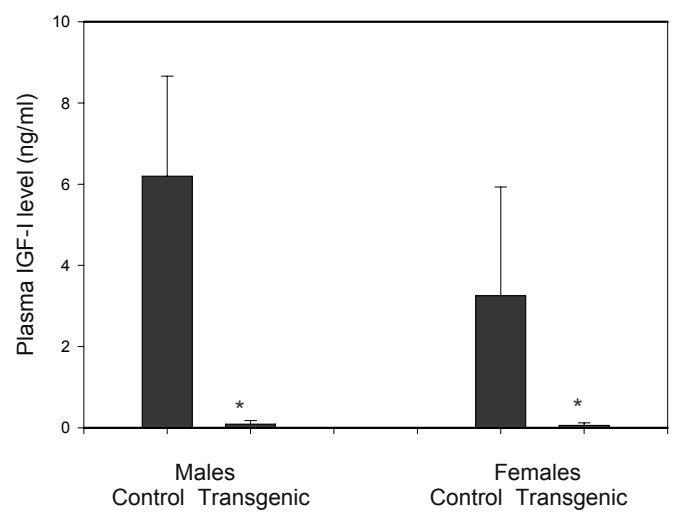

D.

Plasma testosterone level in normal and transgenic male and female rabbits

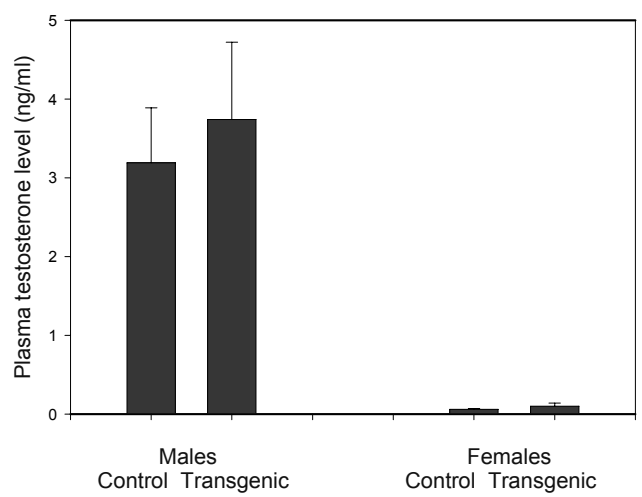

F.

Plasma hFVIII leve

in normal and transgenic male and female rabbits

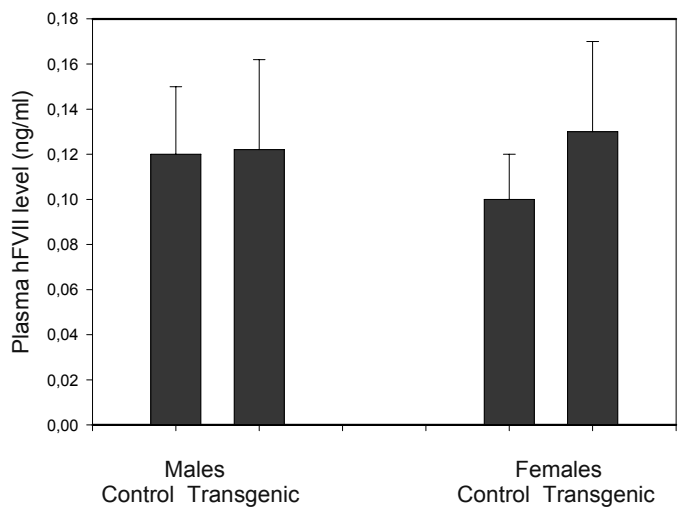

Fig. 1. Concentrations of hormones in blood plasma of adult male and female non-transgenic and transgenic rabbits. Acorticosterone, B - IGF-I, C - progesterone, D - testosterone, E - estradiol, F - hFVIII. Values are means \pm S.E.M. * - significant $(p<0.05)$ differences between control and transgenic animals of the same sex. 
A.

Plasma corticosterone level in normal and transgenic female rabbits

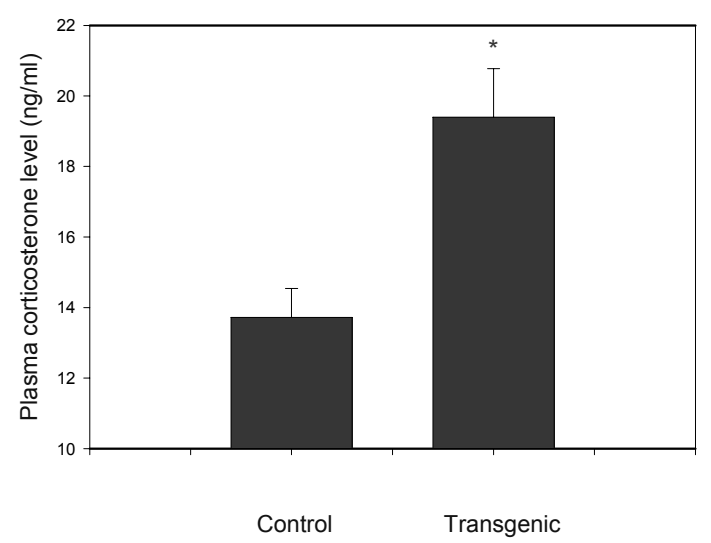

C.

Plasma progesterone level in normal and transgenic female rabbits

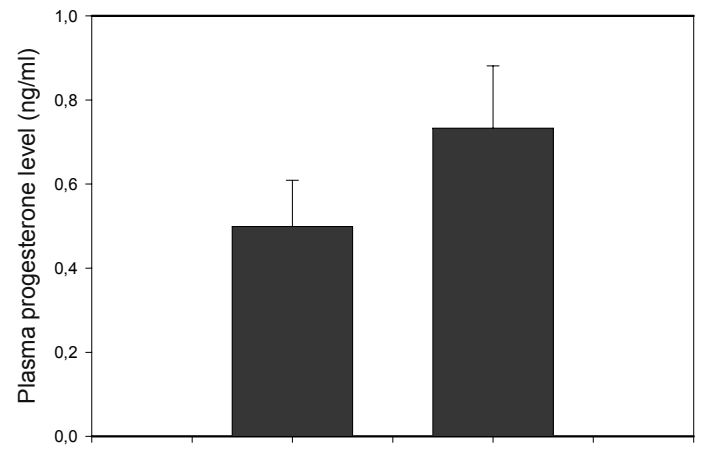

Control Transgenic

E.

Plasma estradiol level in normal and transgenic female rabbits

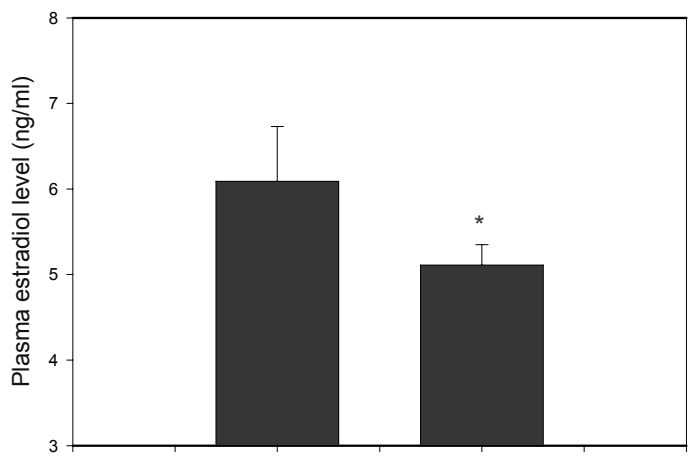

Control Transaenic
B.

Plasma IGF-I level

in normal and transgenic female rabbits

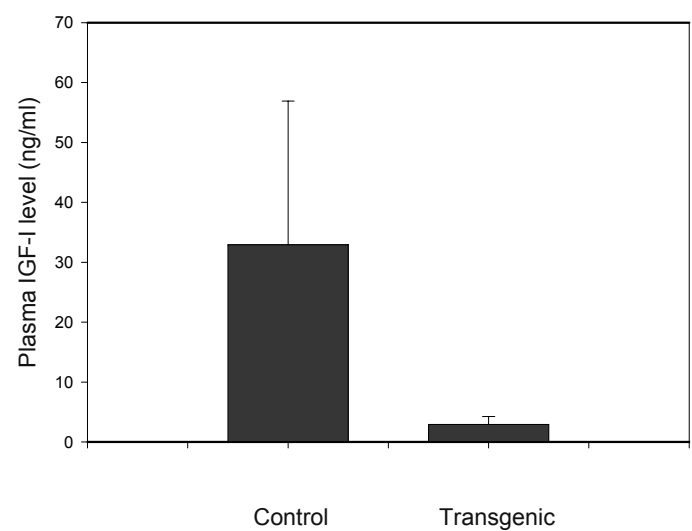

D.

Plasma testosterone level in normal and transgenic female rabbits

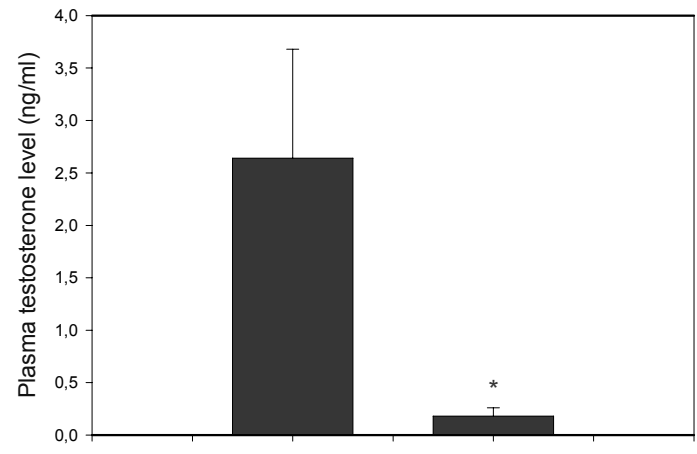

Control Transgenic 
A.

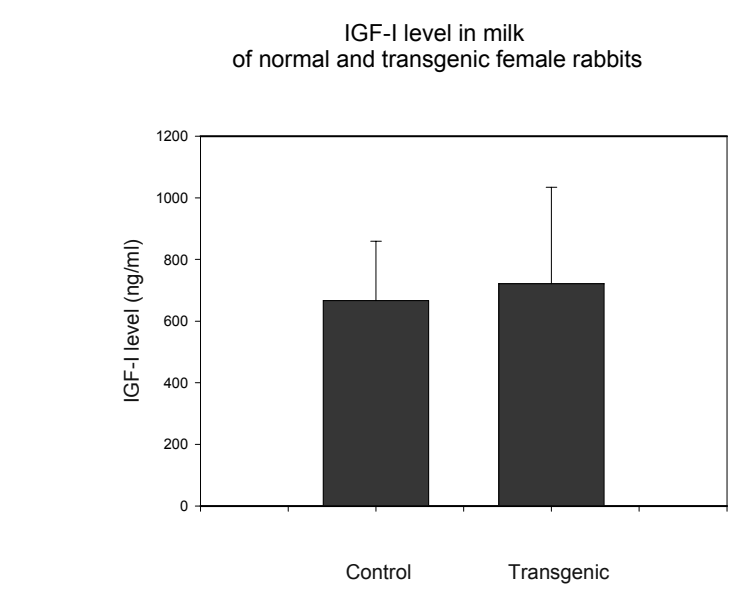

B.

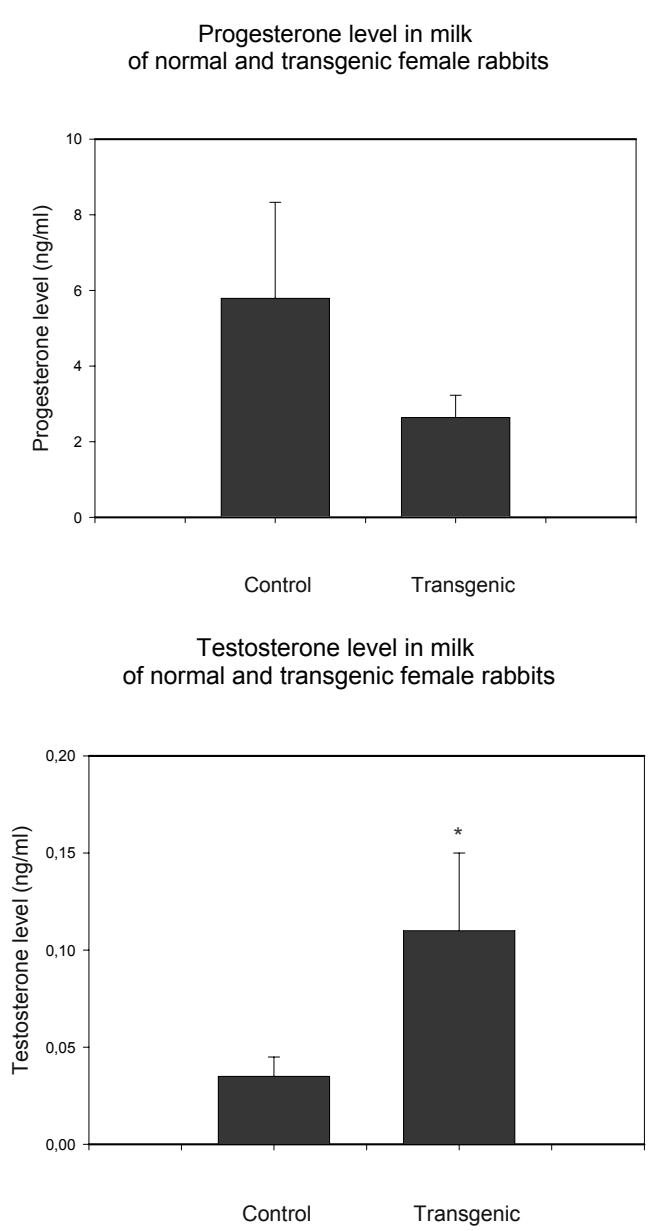

Fig. 3. Concentrations of hormones in milk of adult female nontransgenic and transgenic rabbits. A - IGF-I, B - progesterone, C - testosterone. Values are means \pm S.E.M. * - significant $(p<0.05)$ differences between control and transgenic animals.

The mean concentration of IGF-I in young transgenic animals was lower than in non-transgenic rabbits, but in the controls these differences were statistically insignificant due to large S.E.M. (Fig. 2b). Transgenic young females had significantly less $\mathrm{T}$ (Fig. 2d) and $\mathrm{E}_{2}$ (Fig. 2e) in plasma than non-transgenic animals. No differences in plasma $\mathrm{P}_{4}$ concentration between the groups were observed (Fig. 2c).

Concentration of hormones in milk of transgenic and non-transgenic females

Substantial amounts of IGF-I, $\mathrm{P}_{4}$ and $\mathrm{T}$ were detected in rabbit milk (Fig. 3). No influence of transgenesis on milk concentration of IGF-I (Fig. 3a) and $\mathrm{P}_{4}$ (Fig. 3 b) was detected, but the concentration of $\mathrm{T}$ in milk of transgenic animals was significantly higher that in controls (Fig. 3c).

Some indices of fertility and growth in transgenic and non-transgenic animals

Comparison of number of offspring born by transgenic and non-transgenic females from the third generation of transgenes showed no differences in litter size between the groups (Fig. 4). Measurement of body mass of these offspring showed reduction in this index in male, but not female transgenic pups (Fig. 5).

\section{Discussion}

Our observations confirm previous reports of presence of corticosterone (Aghajafari et al. 2002, Viau 2002, Brecchia et al. 2006) and of gonadal steroids and their sexual differences (Spies et al. 1997, Hillier 2001) in rabbit plasma. This is the first report of the presence of IGF-I and hFVIII-like immunoreactivity in rabbit blood.

Increased amounts of $\mathrm{C}$ in the blood of both adult and young transgenic animals, suggest a higher influence of non-specific stress in transgenic rabbits. Increased $\mathrm{C}$ in these transgenic rabbits was shown to be associated with the occurrence of pathological changes in organs, bones and blood leucocytes, urea and aspartateaminotransferase (Parkányi et al. 2004, Suvegová et al. 2004, Martiniaková et al. 2005). All these observations suggest the existence of some pathological processes or decreased adaptability of transgenic animals in comparison with their non-transgenic relatives. On the other hand, lack of differences in viability of transgenic and non-transgenic rabbits from the same litter described previously (Chrenek et al. 2005a) suggest that the observed changes in physiological and endocrine parameters did not alter the efficacy of adaptive mechanisms or the viability of transgenic animals.

In rabbits, high $\mathrm{C}$ concentration can suppress 
Litter size in normal and transgenic rabbits

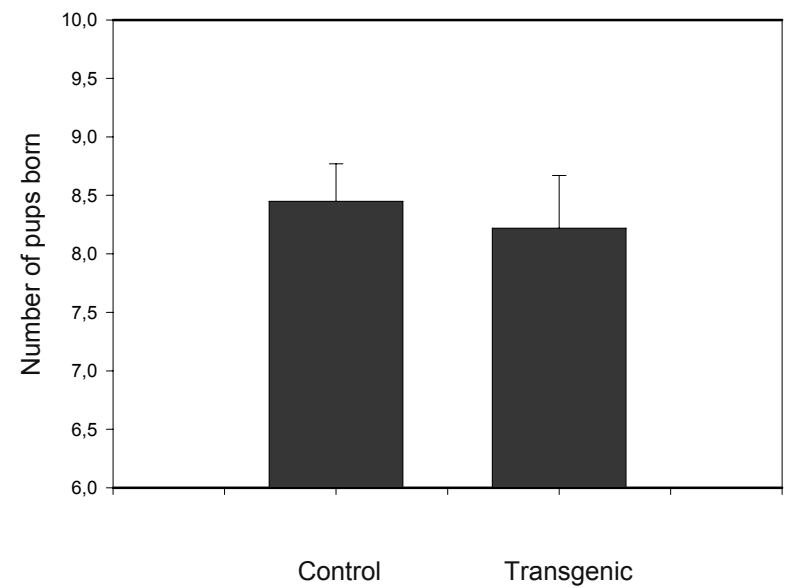

Fig. 4. Litter size in non-transgenic and transgenic rabbits. Values are means \pm S.E.M.

reproduction (Viau 2002, Brecchia et al. 2006) and growth (Aghajafari et al. 2002). It is possible that the increased corticosterone levels observed in our studies could be responsible for altered mobility, concentration, osmolarity and viability of sperm described in these transgenic animals previously (Chrenek et al. 2007). Nevertheless, the observed changes in corticosterone do not seem to affect fertility (litter size) or growth (body mass of pups).

Transgenesis in our experiments was associated with a dramatic decline in plasma IGF-I concentration. Since IGF-I may be a stimulator of growth, reproduction, ovarian secretory activity, adaptogene and anti-apoptotic factors (Makarevich et al. 2000, Fair 2003, Mazerbourg et al. 2003, Oksbjerg et al., 2004), the suppression of some these processes in transgenic rabbits might be expected. On the other hand, transfection-induced overproduction of IGF-I by rabbit mammary gland did not influence their fertility (Zinovieva et al. 1998). In our experiments, reduced IGF-I in transgenic animals was associated with an increased $\mathrm{C}$ concentration in blood. These changes in hormone secretion, together with some signs of pathological changes reported previously (Suvegová et al. 2004), might indicate transgenesisinduced suppression of mechanisms controlling growth, adaptation or repair. This hypothesis was confirmed by lower body mass in transgenic young males, which could be due to reduced plasma IGF-I level, but not to IGF-I received from maternal milk (where IGF-I, in contrast to plasma, was not reduced). These observations confirm the previous report (Zinovieva et al. 1998) of lack of
Litter size in normal and transgenic rabbits

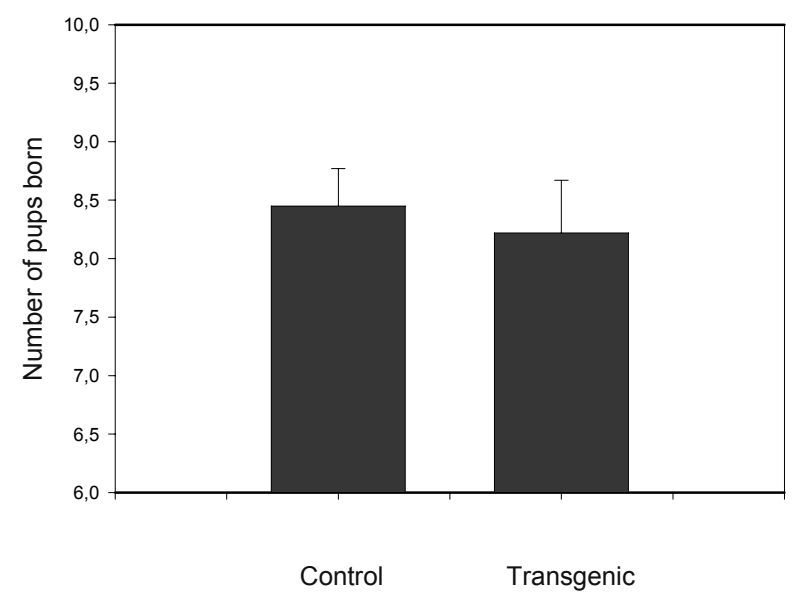

Fig. 5. Body mass of pups (one month of age) of non-transgenic and transgenic male and female rabbits. Values are means \pm S.E.M.

influence of milk IGF-I level on rabbit physiological and reproductive performance.

The differences in $\mathrm{P}_{4}, \mathrm{~T}$ and $\mathrm{E}_{2}$ in blood and milk between transgenic and control animals could indicate some transgenesis-associated changes in secretory activity of both male and female gonads. These differences could be responsible for changes in some gonadal steroid-regulated tissues: the bones (Martiniaková et al. 2005) and sperm (Chrenek et al. 2007) as described previously in these transgenic rabbits. Some of the observed changes in gonadal steroids could be due to changes in their regulators, IGF-I and corticosterone. Nevertheless, the observed transgenesisinduced alterations in plasma progestagen, androgen and estrogen concentration were not associated with significant changes in female fecundity (litter size).

Our observations confirm previous reports (Lo et al. 1999, Davey and MacLean 2006, Palmer et al. 2006) of non-specific changes in transgenic animals seemingly not related to introduced gene. It provides, however, the first data on non-specific inherited effect of transgenesis on endocrine system and growth in rabbits. The present observations suggest that transgenesis in rabbits could be associated with substantial changes in endocrine system (plasma and milk concentration of adrenal and gonadal steroid hormones and growth factor), but not in fertility or growth.

The mechanisms whereby transgenesis affects endocrine traits remain unknown. The introduced WAPhFVIII gene construct did not contain genes regulating substances other than hFVIII. Moreover, it promoted 
production of hFVIII only in mammary gland, but not in other tissues (Chrenek et al. 2005b). The fact that hFVIII is produced only in mammary gland and secretes only to milk but not to other tissues, was confirmed by absence of WAP-hFVIII gene expression in non-mammary tissues, by accumulation of hFVIII in milk (Chrenek et al. 2005b) and by the low concentrations of hFVIII-like immunoreactivity in the blood of both transgenic and non-transgenic animals in our experiments. Therefore, the observed differences between transgenic and nontransgenic animals were not due to hFVIII introduced into somatic cells because hFVIII is absent in males and non-lactating females. Furthermore, these differences could not be an effect of hFVIII taken up from maternal milk because both transgenic and non-transgenic pups from the same litter, the differences between which were described here, were feed with the same milk. Therefore, the observed differences appear to be due to changes induced by transgenesis itself and inherited over several generations. These unknown factors require further study due to the growing importance of transgenesis, the consequences of which on present and future generations should be known and taken into account. Furthermore, the differences in some endocrine and growth parameters observed in our experiments, should be taken into account by production of transgenic animals in future due to potential effect of these hormonal alterations on physiology, adaption, viability, growth and reproduction of transgenic animals in further generations.

\section{Conflict of Interest}

There is no conflict of interest.

\section{Acknowledgements}

The authors express their deep gratitude to Ing. Ž. Kuklová, Mrs. K. Tothová, Mrs. A. Šmondráková and Mr. J. Pecho for skilful technical assistance during experiments and hormone analysis. These studies were supported by Slovak Academy of Science (grant 2003 SP51/028 09 00/028 09 03).

\section{References}

AGHAJAFARI F, MURPHY K, MATTHEWS S, OHLSSON A, AMANKWAH K, HANNAH M: Repeated doses of antenatal corticosteroids in animals: a systematic review. Am J Obstet Gynecol186: 843-849, 2002.

BÖSZE Z, HIRIPI L, CARNWATH JW, NIEMANN H: The transgenic rabbit as model for human diseases and as a source of biologically active recombinant proteins. Transgenic Res 12: 541-553, 2003.

BRECCHIA G, BONNANO A, GALEATI G, FEDERICHI C, MARANESI M, GOBBETTI A, ZERANI M, BOITI C: Hormonal and metabolic adaptation to fasting: effects on thehypothalamic-pituitary-ovarian axis and reproductive performance of rabbit does. Domest Anim Endocrinol 31: 105-122, 2006.

CHRENEK P, VAŠÍČEK D, MAKAREVICH A, JURČÍK R, SUVEGOVÁ K, PARKÁNYI V, BAUER M, RAFAY J, BÁTOROVÁ A, PALEYANDA RK: Increased transgene integration efficiency upon microinjection of DNA into both pronuclei of rabbit embryos. Transgenic Res 14: 417-428, 2005a.

CHRENEK P, KAUFMANN V, MAKAREVICH AV, BAUER M, RYBAN L, UHRÍN P, PALEYANDA RK, BINDER BR: Production of recombinant human clotting Factor VIII in mammary gland of two transgenic rabbit lines. Proc $49^{\text {th }}$ GTH meeting, Mannheim, 2005b, poster P118.

CHRENEK P, TRANDZIK J, MASSANYI P, MAKAREVICH A, LUKÁČ N, PEŠKOVIČOVÁ D, PALEYANDS RK: Effect of transgenesis on reproductive traits of rabbit males. Animal Reprod Sci 99: 127-134, 2007.

DE KLOET ER: Hormones and the stressed brain. Ann N Y Acad Sci 1018: 1-15, 2004.

DAVEY RA, MACLEAN HE: Current and future approaches using genetically modified mice in endocrine research. Am J Physiol 291: E429-E438, 2006.

FAIR T: Follicular oocyte growth and acquisition of developmental competence. Anim Reprod Sci 78: 203-216, 2003.

HILLIER SG: Gonadotropic control of ovarian follicular growth and development. Mol Cell Endocrinol 179: 39-46, 2001.

LO D, FENG L, LI L, CARSON MJ, CROWLEY M, PAUSA M, NGUEN A, REILLY CR: Integrating innate and adaptive immunity in the whole animal. Immunol Rev 169: 225-239, 1999.

MAKAREVICH A, SIROTKIN AV, CHRENEK P, BULLA J, HETÉNYI L: The role of IGF-I, cAMP/protein kinase A and MAP-kinase in the control of steroid secretion, cyclic nucleotide production, granulosa cell proliferation and preimplantation embryo development in rabbits. J Steroid Biochem Mol Biol 73: 123-133, 2000. 
MAKAREVICH AV, SIROTKIN AV, GENIESER HG: Action of protein kinase A regulators on secretory activity of porcine granulosa cells in vitro. Anim Reprod Sci 81: 125-136, 2004.

MARTINIAKOVÁ M, OMELKA R, CHRENEK P, RYBAN L, PARKÁNYI V, GROSSKOPF B, VONDRÁKOVÁ M, BAUEROVÁ M: Changes of femoral bone tissue microstructure in transgenic rabbits. Folia Biol (Praha) 51: 140-144, 2005.

MAZERBOURG S, BONDY CA, ZHOU J, MONGET P: The insulin-like growth factor system: a key determinant role in the growth and selection of ovarian follicles? A comparative species study. Reprod Domest Anim 38: 247258, 2003.

OKSBJERG N, GONDRET F, VESTERGAARD M: Basic principles of muscle development and growth in meatproducing mammals as affected by the insulin-like growth factor (IGF) system. Domest Anim Endocrinol 27: 219-240, 2004.

PALMER CA, NEVILLE MC, ANDERSON SM, MCMANAMAN JL: Analysis of lactation defects in transgenic mice. J Mammary Gland Biol Neoplasia 11: 269-282, 2006.

PARKÁNYI V, CHRENEK P, RAFAY J, SUVEGOVÁ K, JURČÍK R, MAKAREVICH AV, PIVKO J, HETÉNYI L, PALEYANDA RK: Aneuploidy in the transgenic rabbit. Folia Biol (Praha) 50: 194-199, 2004.

SIROTKIN AV, MAKAREVICH AV, KOTWICA J, MARNET P-G, KWON HB, HETENYI L: Isolated porcine ovarian follicles as a model for the study of hormone and growth factor action on ovarian secretory activity. J Endocrinol 159: 313-321, 1998.

SPIES HG, PAU KY, YANG SP: Coital and estrogen signals: a contrast in the preovulatory neuroendocrine networks of rabbits and rhesus monkeys. Biol Reprod 56: 310-319, 1997.

SUVEGOVÁ K, JURČÍK R, CHRENEK P, VAŠÍČEK D, GAŽIČOVÁ Z, RAFAY J, HANUŠOVÁ E: Comparison of inner organs weight and selected hematological and biochemical blood parameters of transgenic and nontransgenic rabbits. Proc 8th World Rabbit Congress, Mexico, 2004, pp 632-638.

TUDDENHAM EGD, COOPER DN, GITSCHIER J, HIGUCHI M, HOYER LW, YOSHIOKA A, PEAKE IR, SCHWAAB R, OLEK K, KAZAZIAN HH, LAVERGNE JM, GIANNELLI F, ANTONARAKIS SE: Haemophilia A: database of nucleotide substitutions, deletions, insertions and rearrangements of the factor VIII gene. Nucleic Acids Res 19: 4821-4833, 1991.

VIAU V: Functional cross-talk between the hypothalamic-pituitary-gonadal and -adrenal axes. J Neuroendocrinol 14: 506-513, 2002.

ZINOVIEVA N, LASSNIG C, SCHAMS D, BESENFELDER U, WOLF E, MULLER S, FRENJO L, SEREGI J, MULLER M, BREM G: Stable production of human insulin-like growth factor 1 (IGF-1) in the milk of hemiand homozygous transgenic rabbits over several generations. Transgenic Res 7: 437-447, 1998. 